\title{
Editorial: Themed issue on gender mainstreaming in rural transport
}

Annabel Bradbury PhD

Deputy Team Leader, ReCAP, London, UK (corresponding author: annabel.bradbury@cardno.com)
Gina Porter PhD

Professor, Department of Anthropology, Durham University, UK
Gender mainstreaming was established as an intergovernmental mandate in the Beijing Declaration and Platform for Action in the Fourth World Conference on Women in 1995 (UN, 1995). While there has been some progress in mainstreaming, the UN sustainable development goals acknowledge that gender inequality remains a key challenge. Nowhere is gender mainstreaming more urgently needed than in the transport sector, where gender inequality and inequity continue to inhibit development progress in low-income countries. Despite many initiatives highlighting the different mobility needs and patterns of women and men, transport policies continue to fall short of the strategic objectives and actions of the Beijing declaration, especially regarding women and poverty reduction.

The UK Aid-funded Research for Community Access Partnership (ReCAP) programme, recognising the urgent need for action, launched its gender mainstreaming research initiative in 2015. The initiative sits well within ReCAP's overall aim of promoting safe and sustainable transport for rural communities in Africa and Asia. ReCAP acknowledges that rural transport infrastructure and transport services can impact women and men very differently, and that many interventions more directly support men's needs. The initiative thus aims to increase the body of evidence available to policy makers and practitioners involved in gender mainstreaming in rural transport, and also to build a better understanding of why gender mainstreaming progress to date has so often been slow, despite national commitments towards gender-sensitive planning and practice.

Following a competitive call, ReCAP commissioned seven research teams to explore gender issues and gender mainstreaming progress in the rural transport sector in eight ReCAP partner countries: Ghana, Kenya, Uganda, Tanzania, Ethiopia, Liberia, Sierra Leone and Nepal. This themed issue documents their findings, typically based on small studies extending over one year. The papers highlight many themes that have appeared with remarkable regularity across diverse African and Asian contexts, in particular

- women's time constraints (often including unpaid care work) that prevent their active participation in road construction and associated skills training

- women's lack of voice in key decision-making processes

- inadequate field monitoring of the application of national gender mainstreaming regulations in transport projects
- the lack of women in technical and policy roles in the sector, where they might offer strong role models

- the perception that transport services operations are a male domain unsuited to women

- women's lack of resources to pay transport fares

- women's concerns about male harassment when travelling.

Six of the research teams were led by in-country staff of international non-governmental organisations (NGOs) and one team was university-led. However, all the NGO-led teams were able to access, where appropriate, small supporting inputs into project design, methodology, data analysis and writing from an academic researcher. The resulting papers demonstrate the potential of NGO-academic collaborations for producing strong, field-based research. Field research methodologies were typically built around qualitative, one-to-one interviews and focus groups (sometimes encompassing innovative approaches rarely encountered in transport studies - home stay 'immersions', peer research, photovoice). In some studies, these were supplemented by small quantitative surveys. Most of the papers span gender issues relating to both infrastructure (roads/bridges) and associated transport services - they thus encourage attention to vital interlinkages that civil engineers rarely fully appreciate or engage with.

All the papers in this themed issue take a multi-level approach, so that findings are well contextualised within wider national policy settings. However, three of the papers put a particularly strong focus on attention to national gender mainstreaming policies and their application in rural contexts. The broadest review, by Njenga and Tanzarn (2020), compares policies and practice in four countries - Ghana, Uganda, Kenya and Tanzania. They conclude that all have constitutional, policy and legislative frameworks that underpin gender equality principles and, moreover, there is positive integration of gender across the project cycle in the programmes they reviewed in depth. At the same time, however, they note that these case studies were focused on donor-funded programmes where the donors' gender policy will likely have had some impact. Even in the projects reviewed there were weaknesses in gender reporting, knowledge sharing and gender policy advocacy. Njenga and Tanzarn suggest that one of the underlying reasons for the low visibility of gender mainstreaming activities is a lack of knowledge regarding how to set clear gender objectives and measurable indicators and the capacity to monitor gender outcomes and impacts. 
In-depth work conducted in Kenya and Tanzania provides further balance because it extends to detailed field analysis of national framework impacts outside of donor-funded programmes. In Kenya, a multi-level case study at national and county level carried out by Nyangueso et al. (2020) demonstrates that gender mainstreaming is inadequately understood by most transport sector institutions and gender-disaggregated data are not easily available or applied; the extreme shortage of women engineers working at technical, executive and managerial levels is identified as a key factor inhibiting progress. Similarly, in Tanzania, while there are national regulations in place regarding women's employment in the transport sector, there are insufficient resources to collect adequate gender-disaggregated data and monitor and enforce regulations regarding women's employment on road contracts or other aspects of potential road-related benefits for women (e.g. inputs into road planning) (Mulongo et al., 2020). Mulongo et al. report that community- and district-generated road projects are particularly open to male capture. The sparsity of women engineers is a further constraint here, as in Kenya.

Issues around gendered employment practice in the construction sector are highlighted in most papers. National governments commonly legislate for equal employment opportunities for men and women and often will further require affirmative action for women in recruitment and training. However, this is only rarely adequately implemented on the ground, not only as a result of male resistance to employing women but also because women's participation may be constrained by competing time demands, including the provision of care to children and elders, all of which can exacerbate tensions in the household. These points are particularly strongly emphasised in both the Nepal studies. Although project quotas have expanded women's participation in basic labouring work in road and bridge projects in the two rural districts researched by Hada (2020) women's domestic duties have limited the scale of uptake, while distance to training facilities has limited their movement into higher-paid skilled work. Nonetheless, the new income-earning opportunities made available, especially through quotas and equal pay as labourers on the projects, have enabled some change in consumption patterns (notably increased meat consumption), encouraged a shift from subsistence farming towards cash crops and increased employment in the service sector. There has been a significant increase in some female ownership of assets (gold, livestock, mobile phones, small businesses) and women's status and confidence have also increased because these income-earning activities take place outside the home. Nevertheless, men continue to dominate community and district decision-making in Nepal.

The stress of women's domestic burdens when new employment opportunities emerge, as emphasised by Hada, is mirrored in the analysis of the Nepalese government's trail bridge programme by Sherpa et al. (2020). Research in all three ecological regions found some women failing to participate because of domestic chores (such as carrying fuelwood and fodder) and others participating only by taking on an even greater workload or through the redistribution of domestic work to other family members, including girl children; none of these strategies appear advantageous to women overall. Issues associated with safe, conducive work environments for women (including gender-friendly latrines and crèche facilities) are noted as of concern to women in many of the papers.

National gender mainstreaming programmes tend to focus on women per se, but it is crucial that the diversity among women and potential vulnerabilities among other disadvantaged groups is given adequate attention in transport contexts. Thus, while gender-responsive budgeting has supported women's employment opportunities, especially in construction, and has thus opened chances to earn income, it has largely excluded women with intersecting vulnerabilities such as older people, female heads of households and people with disabilities. Specific efforts are made to identify the variation in needs and vulnerabilities in the paper on Ethiopia (Abhishek et al., 2020), which argues for the importance of distinguishing between the experiences and needs of men, women in male-headed households and women in women-headed households with regard to the planning, construction and use of rural roads. As was noted with respect to road construction in Nepal, this is directly related to women's time poverty and lack of access to resources.

In the Tanzanian study, Mulongo et al. (2020) similarly place particular emphasis on understanding the experiences and needs of women with multi-dimensional vulnerabilities who often face multiple forms of discrimination, such as those living with HIV and/or disabilities, older women and widows. Mulongo et al. also point to the value of training such people as co-researchers in order to gain a fuller understanding of how such disadvantages impact their lives. With regard to marginalised women in the two Tanzanian study districts, only the Tanzania Social Action Fund road projects seem to have brought some benefit (in one district). In Nepal, where caste-based discrimination still plays a significant role in women's lives and well-being, the studies of both Hada (2020) and Sherpa et al. (2020) refer to how socially marginalised Dalit women may gain particular resources and skills through road construction work: indeed, as noted by Hada, such skills and work opportunities may sometimes be spurned by people from better-off groups.

Much has been said to this point about the limitations of gender mainstreaming presented in these papers, but it is also important to note that, despite such failures, there can still be advantages (often incidental and unplanned) for some women regarding access to services when transport infrastructure interventions take place. This may occur even if, as is commonly the case, they have been sidelined in the road planning process - despite legislation to the contrary - by, for instance, timing meetings when women are busy at home or by ignoring their voices. Thus, in rural Tanzania, where barely any women operate motorised commercial transport services (as is widely the case across Africa), those 
women with the funds and independence to access the expanded transport services that tend to follow on from road improvements report considerable benefits (Mulongo et al., 2020). These include faster and smoother travel, improved access to farms and markets, health and education services, sometimes lower transport costs as services expand and better provision of goods and services in the villages. Increased access to care services was also reported for people with disabilities following infrastructure improvements, and wheelchair users noted the benefits of smoother road surfaces. In rural Nepal (where similarly few women own or drive vehicles), better roads have enabled only a minority of women to travel more; the main benefit for women regarding road use reported by Hada (2020) is improved access to hospitals in an obstetric emergency. However, the construction of trail bridges in Nepal's mountainous regions is of crucial importance to pedestrians of both genders for accessing food supplies, markets and health and education services (Sherpa et al., 2020).

Regarding women's access to road transport in rural Africa, one major development in recent years has been the massive expansion of motorcycle taxi services in many countries (promoted by the availability of cheap imported motorcycles). The final paper in this themed issue (Jenkins et al., 2020) shows how, in the particularly difficult post-conflict contexts of Liberia and Sierra Leone, where rural paved roads are still sparse, the availability of motorcycles has transformed livelihood opportunities for many women. Impacts on women here are far more dramatic than in Tanzania, for instance, where high fares tend to limit women's use to emergency situations (Mulongo et al., 2020). As a result of the growth in rural motorcycle taxi services, social attitudes are changing rapidly in Liberia and Sierra Leone, and many village women are now able to combine household and childcare responsibilities with participation in petty trade. Women perceive speedy access to local markets and maternal health care as paying motorcycle passengers to be of immense benefit. This is the case, even though all motorcycle drivers currently are men and most (not all) motorcycles are also owned by men. Interestingly, the study also explores the potential to introduce women operators ('riders') with a scheme whereby women would obtain a motorcycle to use for commercial purposes on credit. There seems good support for such an experiment given that many women would prefer to travel with a woman rider, although there are also potential constraints associated with safety, security and local socio-cultural perspectives.

To summarise, while the study countries covered in this themed issue were found to be generally progressive in terms of formulating gender and social inclusion policies, the execution of these policies and the uptake and embedment of inclusive legislation have clearly been deficient to date, despite the desire of many rural women for improved access to services, markets and income. For women's increased involvement in roadworks, and their expanded participation in community meetings and wider decision-making around transport planning, an increase in men's awareness of women's rights to a more active role in household and community affairs will be essential. Not least, this will require men to take on and share more household responsibilities.

We hope you will find the papers in this themed issue of Transport inspiring and an encouragement to championing further research and action into the changing landscape of gender equality and equity in transport and its influence on poverty reduction. We recommend that you also refer to the Guidelines for Mainstreaming Gender in Rural Transport (Tanzarn, 2019). These guidelines, which include good practice examples and transferable illustrations of initiatives that promote inclusive and equitable transport, draw extensively on the detailed field reports that formed the base for the papers in this themed issue (all accessible from the ReCAP website (ReCAP, 2020)). As Tanzarn concludes, gender mainstreaming is an obligation and responsibility of the transport sector. Most initiatives do not challenge the status quo; some continue to accommodate the prevailing power dynamics between women and men, perpetuating stereotypes and heightening gender inequalities such as women's time poverty. Radical change is long overdue.

\section{REFERENCES}

Abhishek A, Borgia C, Manjur K, van Steenbergen F and Vera LF (2020)

Gender mainstreaming in rural road construction/usage in Ethiopia: impact and implications. Proceedings of the Institution of Civil Engineers - Transport 173(2): 122-131, https://doi.org/ $10.1680 /$ jtran.18.00154.

Hada JD (2020) Gender mainstreaming in the Nepalese rural transport sector: working towards transformative change. Proceedings of the Institution of Civil Engineers - Transport 173(2): 97-106, https://doi.org/10.1680/jtran.18.00177.

Jenkins J, Mokuwa EY, Peters K and Richards P (2020) Changing women's lives and livelihoods: motorcycle taxis in rural Liberia and Sierra Leone. Proceedings of the Institution of Civil Engineers - Transport 173(2): 132-143, https://doi.org/10.1680/jtran.18.00162.

Mulongo G, Porter G and Tewodros A (2020) Gendered politics in rural roads: gender mainstreaming in Tanzania's transport sector. Proceedings of the Institution of Civil Engineers - Transport 173(2): 87-96, https://doi.org/10.1680/jtran.18.00153.

Njenga P and Tanzarn N (2020) Scaling up gender mainstreaming in transport: policies, practices and monitoring processes. Proceedings of the Institution of Civil Engineers - Transport 173(2): 64-75, https://doi.org/10.1680/jtran.18.00152.

Nyangueso SO, Orwa SO, Ombai M and Sheba S (2020) Effects of gender mainstreaming efforts on rural transport institutions in Kenya. Proceedings of the Institution of Civil Engineers - Transport 173(2): 76-86, https://doi.org/10.1680/jtran.18.00146.

ReCAP (Research for Community Access Partnership) (2020) http://www. research4cap.org/SitePages/Home.aspx (accessed 29/01/2020).

Sherpa M, Tumbahangfe A, Acharya N et al. (2020) Transforming gender relations in Nepal's trail bridge programme: policies and practice. Proceedings of the Institution of Civil Engineers - Transport 173(2): 107-121, https://doi.org/10.1680/jtran.18.00183.

Tanzarn N (2019) Guidelines for Mainstreaming Gender in Rural Transport. Research for Community Access Partnership (ReCAP) for the Department for International Development, London, UK, GEN2157A.

UN (1995) Beijing Declaration and Platform of Action. See https://www. un.org/en/events/pastevents/pdfs/Beijing_Declaration_and_ Platform_for_Action.pdf (accessed 16/10/2019). 